\title{
Estudio del Reglamento de la Hacienda municipal de Barcelona
}

\author{
por \\ JOSE BARRUBES ORIOL \\ A bogado \\ Seerotario do Seguada Categorla do Adminietraelón Local
}

Como dijo nuestro Allcalde, Barcelona se encontraba y se encuentra todavía, en una delicada situáción. Su término municipal. de $97,62 \mathrm{~km}^{2}$ está prácticamente agotado; pero en cambio su crecimiento demográfico es vertiginoso. Según estadísticas referidas al 31 de diciembre de 1959 , el aumento fue de 35.398 almas, de las que II.556 corresponden all crecimiento vegetativo y el resto a la inmigración. La población de hecho era en el citado año de 1.538.710, to que supone una densidad de 15.762 habitantes por $\mathrm{km}^{2}$, que pasa a ser de $16.886 \mathrm{hab} / \mathrm{km}^{2}$ si de la superficie total deduicimos $10 \mathrm{~s} 6,5 \mathrm{ki}$ lómetros destinados a zona verde (I).

El coste die las viviendas necesarias se calcula en 1.665 millones de pesetas, más unos 300 pará gastos de urbanización y otros tantos para servicios complementarios.

En contraposición, los recursos económioos tienen una marcada tendencia a disminuir. En 1958 la recaudación líquida total fue de I.189.644.020, 18 pesetas, con un aumento respecto ail año anterior

(1) El año 1900 Barcelona tenía una población de 537.354 habitantes; en lo que va de siglo se ha triplicaido. Las regiones que dan mayor contingente de inmigración son, de mayor a menor: Andalucla, las dos Castillas, Aragón, Galicia, León, Valencia y Murcia." 
de 222.759.291,05 pesetas; sin embargo, la de 1959 sólo superó a la de 1958 en $63.692 .855,48$ pesetas.

Para remediar la situación se hacía indispensable da adecuación de la normatividad existente a la realidad social; puesto que -según el Profesor Ruiz del Castillo- el Municipio es una entidad sociológica dotada de un régimen jurídico, el cual, para ser auténtico, ha de acomoldarse a la realidad subyacente a que se aplica.

La solución no podía hallarse en los estrechos cauces de un régiınen de Carta, sino en los más amplios y flexibles de una Ley especial orgánica y económica que se atemperase a las complejas necesidades y a la peculiar idiosincrasia de la ciudad condal. Para ello no se ha echado mano de patrones exóticos, sino que "se han buscado soluciones españolas»).

Barcelona con su desbondante vitalidad ejerce una influencia notoria sobre un cinturón de 26 Municipios, con algunos de los cuales (Prat de Llobregat, Hospitaliet de Llobregat, San Adrián del Besós y Badalona) está unida sin solución de continuidad (2). Mas a pesar de ello, para resolver los problemas comunes - urbanismo, abastecimiento de agua, transiportes, etc.- a todas las entidades que constituyen la Comarca de Barcelona, no se ha seguido un oriterio absorcionista, al estilo de Madrid, con los graves inconvenientes que lleva consigo la hipertrofia municipal, sino que se ha ido a la creación de una Mancomunidad de Municipios que culmine en el superMunicipio tal como lo concebía Adolfo Posada.

Plor Decreto del Ministerio de Hacienda de 9 de noviembre. de 196I ha sido aprobado el Reglamento de la Hacienda municipal de Barcelona que desarrolla el título $3 .^{\circ}$ de la Ley especial. El Reglamento está dividido en tres títulos, éstos a su vez en capítulos y sec-

(2) Integran la Comarca los siguientes Municipios: Castelldefels, Gavá, Viladecáns, San Clemente de Llobregat, San Baudilio de Llobregat, Prat do Llobregat, San Feliú de Llobregat, Hospitalet de Llobregat, Cornellá, Esplugas, San Juan Despí, San Justo Desvern, ISan Vicente del Honts, Santa Coloma de Cervello, Pallejá, Papiol, Molfns de Rey, San Cugat del Vallés, Sardanyola, Ripollet, Moncada, Reixach, Santa Coloma de Gramanet, San Adrián del Besós, Badalona, Mongat y Tiana, con una superficie total de $390,70 \mathrm{ki}-$ lómetros cuadrados y una población de $426.7^{29}$ habitantes. 
ciones, con un total de 114 artículos, 2 disposiciones finales y 6 transitorias. Los dos primeros artículos constituyen su parte dogmática en cuanto contienen los principios que han de informar la aplicación y la interpretación de las restantes disposiciones del Reglamento.

El sistema impositivo municipal que regula el Reglamento será de aplicación a la totalidad dell' territorio comprendido identro de los limites del término municipal de Barcelona, con excepción de ciertas zonas de dominio nacional y uso público. También se aplicará a los Municipios que, segrún le Ley de 3 de diciembre de 1953, integran la Comarca de Barcelona, de modo que exista entre todos ellos la debida paridad fiscal.

E1 nuevo régimen fiscal trata de corregir lios defectos apuntados más arriba y señailados en la exposición de motivos de la Ley especial. Para ello ia imposición se configurará de manera que recaiga sobre la riqueza situaida o sobre las actividades que se desarrollen en el término municipal, evitandı su traslación a otros Municipios.

El Ayuntamiento no se sujetará a ningún orden prelativo en la aplicación de los recursos tributarios, siendo inoperantes en este punto los artículos 578 y siguientes de la Ley de Régimen local.

Las exacciones municipales se perciben hoy por II 5 conceptos distintos; 28 de los ouales recaen sobne ta propiedad urbana, 31 sobre el comercio y la industria, 31 sobre el consumo y 25 sobre otros varios reoursos. Para evitar la dispersión tributaria y la proliferación de documentos recaudatorios la Ley sienta el principio de que los sistemas de exacción se estructurarán de fonma que procuren la máxima economía.

De acuerdo con el principio de economía y simplificación, la exacción de los derechos $\mathrm{y}$ tasas y de cualquier otra forma de imposición que grave la propiedad inmobiliaria, o las actividades y beneficios comercialies e industriales, se unificará, inclus o con carácter de arbitrio, por su totall importe, recaudándose mediante un solo recibo; también podrán nefundirse -previa autorización del Ministerio de Hacienda- con el tributo base.

Los tributos refundibles deberán recaer, como es lógico, sobre bases análogas e igual sujeto pasivo; pero con la limitación de que la refundición no implicará en el momento de su implantación un gravamen glaball de importe superior al del conjunto de las exac- 
ciones refundidas, debiéndose ajustar las nuevas tarifas a esta limitación.

Los principios de economía, racionailización y eficacia, encuentran su aplicación en el precepto del artículo $4 .^{\circ}$, párrafo $5 .^{\circ}$, del Reglamento, según el cual, las Ordenanzas correspondientes a los tributos unificados poidrán a su vez refundirse en una sola comprensiva de los diversos conceptos impositivos; y en el artículo 68 que faculta al Ayuntamiento para aprobar una Ordenanza general con normas comunes a las distintas exacciones.

Expresión de la justicia sacial que anima el Reglamento, tendente a lograr una justa distribución de las cargas fiscales y la reducción de la presión tributaria indirecta, es la exención total de los arbitrios y tasas que pesan sobre patatas, verduras, huevos y leche, artículos de primera necesiddar que por sí mismos no son índices de capacidad tributaria.

El Reglamento sienta el principio del maximalismo irrebasable de los tipos impositivos, apartándose en este extremo de la dogmática de la Ley de Régimen local.

La delimitación del campo impositivo estatal y local ofrece graves dificultades ya que la misma fuente tributaria soporta el gravamen de varios impuestos, unos de naturaleza estatal y otros de carácter locall. Para impedir que los sistemas tributarios de ambas Haciendas se hallen en pugna, la Ley y el Reglamento aceptan el principio de coondinación entre ambos sistemas fiscalles. Esta coordinación es tanto más necesaria cuanto que los fines fundamentales de toda política financiera son: elevar al máximo posible el producto nacional, hacer que dicho producto se reparta entre los habitantes del pais $\mathrm{y}$ reducir a sus justos límites la presión tributaria.

Según el artículo $3 .^{\circ}$ del Reglamento en relación con los artículos 429 y 435 podemos establlecer el siguiente cuadro sinóptico de los recursos que constituyen la Hacienda del Municipio de Barcelona:

Productos de su patrimonio.

Rendimientos de servicios y explotaciones.

Subvenciones, auxilios y donativos. 


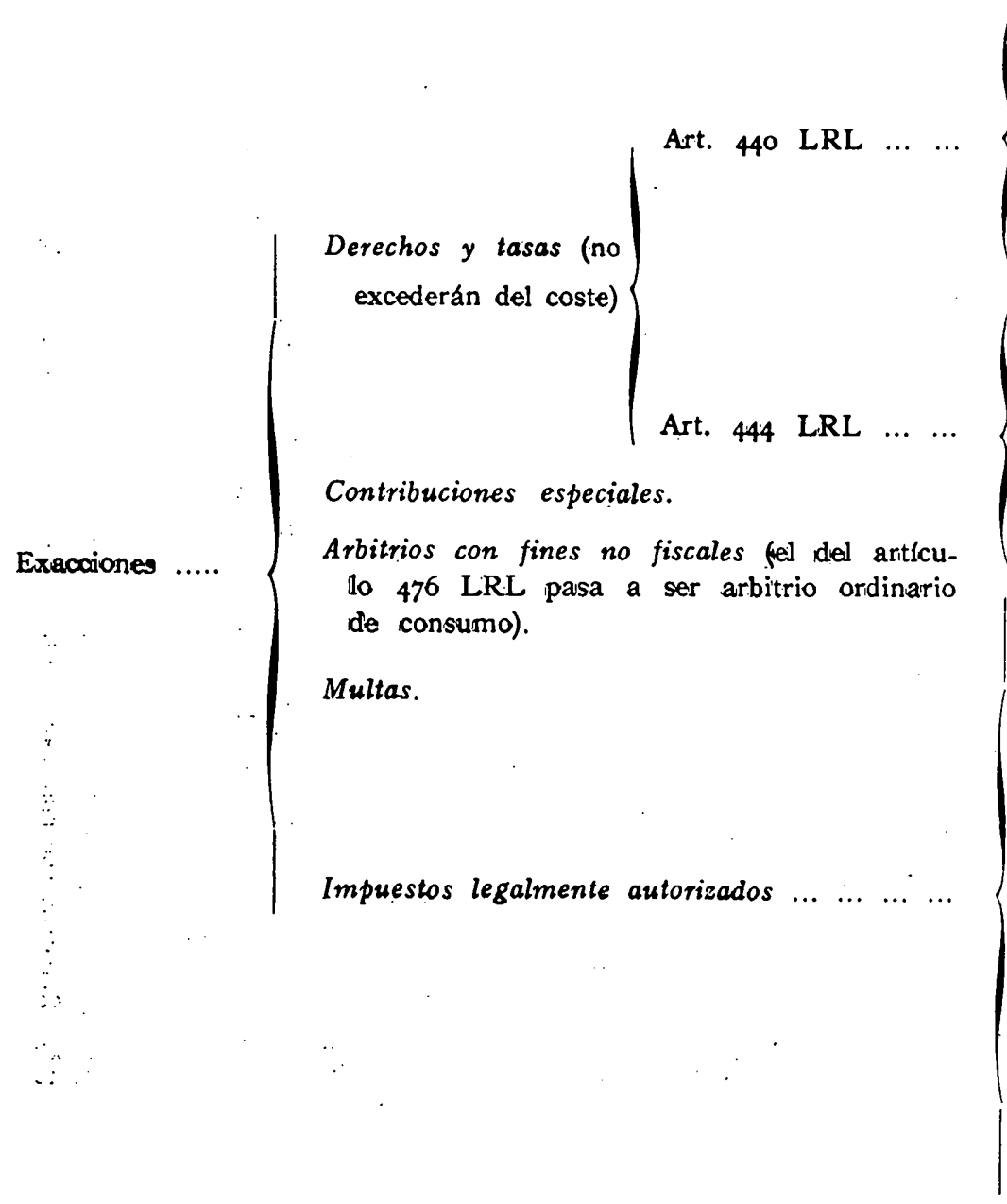

Números 14 y 15 refunden en la tasa do saneamiento y limpieza; números 5 y 8 pasan a ser arbitrio $y$ se exigirán por tarifa ad valorem; número 9 se acumula al anbitrio sobre niqueza urbana; números 6 , 9 y 10 son absorbidos por arbitrio de radicación; número 2 es absorbido por la tasa de estacionamiento de vehículos.

Números 5, il y i2 se acumulan al arbitrio sobne riqueza urbana; números 12 y 23 que recaigan sobre empresas industriales y mercantiles sujetas a radicación quedan absorbidas por éste; números 10, 19 y $24 \mathrm{y}$ arbitrio diel artículo 498 LRL quedan absombidos por tasa estacionamiento de vehículos.

Impuestos cedidos por $\{$ Tarifa V U'sos y Con. el Estado ........ .4 sumos.

Recargos sobre contri. ( Impuesto 3 por 100 buciones e impues- sobre el praducto tos estatales ... taciones mineras.

Recargo sobre el arbitnio provincial que grava el producto neto.

Participación en el anbitrio sabre riqueza pra vinoial.

Participación en la contribución riqueza rús. tica.

Impuestos especiales concedidos por el artículo $4^{1}$ Reglamento Hacienda.

Arbitrios. 
JOSÉ BARROBES ORIOL

Siguiendo al Profesor Saura Pacheco, podemos llegar a la siguiente olasificación de los impuestos dírectos e indirectos dentro del presupuesto municipal.

\section{Impuestos directos}

Art. $1 .{ }^{\circ}-$ Sobve el producto y renta.

Recargo sobre ia licencia fiscal del impuesto sobre actividades y beneficios industriales y comerciales, y del impuesto sobre los rendimientos del trabajo personal (profesionales).

Recargo sobre el impuesto que grava los nendimientos del trabajo personal y en el impuesto sobre las rentas de Sociedades y Entidadles juridicas.

Recargo del $25 \%$ en el arbitrio provincial sobre el producto neto.

Anbitrio sobre la contribución territorial riqueza urbana.

Arbitrio sobre la contribución territorial riqueza rústica.

Recargo :o \% sobre las cuotas del Tesoro de la cuntribución urbana e impuesto industrial $(*)$.

Recargo $10 \%$ sobre impuesto que grava las Sociedades, y sobre la licencia fiscal dei impuesto sobre rendimiento del trabajo personal (art. 486 de la Ley de Régimen iocal) (*).

Recargo $\mathbf{j} \%$ sobre ciertos arbitrios municipales $\left(^{*}\right)$.

Recargo $4 \%$ sobre contribución territorial riqueza urbana $\left(^{* *}\right)$.

Arbitrio sobre ordenación urbanistica, sobre el aumento del volumen de edificación, sobre edificación deficiente $\left({ }^{* *}\right)$.

Art. 2. ${ }^{\circ}$ - Sobre el capital.

Arbitrio sobre solares sin edificar.

Arbitrio sobre incremento valor de los terrenos.

Arbitrio sobre incrementio valor de traspaso de locales de negocio.

Arbitrio de nadicación.

Arbitrio sobre solares edificados y sin edificar $\left(^{*}\right)$.

Recargo $25 \%$ del arbitrio sobne el incremento del valor de los terrenos $(* *)$.

(*) Recursos especiales para amortización de empréstitos.

(") Recursos especiales que nutren el presupuesto especial de Urbanismo. 


\section{Impuestos indirectos}

Articulo único.-Impuestos indirectos.

Contribución de Usos y Consumos. Tarifa V.

Impuesto sobre el vino y la sidra.

Recargo sobre el impuesto que grava el gas y la electricidad.

Recargo sobre ei impuesto del $3 \%$ que grava el producto bruto de las explotaciones mineras.

Arbitrio sobre casinos y circulos de recreo.

Arbitrio sobre el consumo de bebidas espirituosas y alcoholes.

Arbitrio sobre el consumo de carnes, volatería y caza menor.

Arbitrio sobre el consumo die pescados y marisoos finos.

A.rbitrio sobre las pompas fúnebres.

Arbitrio sobre traviesas en espectáculos.

Arbitrio sobre servicios y addquisiciones.

Arbitrio sobre estancias.

Los servicios públicos divisibles se retribuyen mediante tasas y representan una parte del costo de producción. Si la tasa excede de este costo, es evidente que el sobrante servirá para sufragar gastos de servicios públicos generales, con lo que adoptarán el carácter de arbitrio.

Se comprende que solamente por la poisición de monopolista en que está situada la entidad local, puede ser posible la fijación de precios que no corresponidan a los de coste de la unidad consumida de que se trate; pues si imperase la libre concurrencia, se veria el Municipio en la necesidad de aplicar a cada servicio el precio de coste.

La teoría de las tasas tal como escuetamente se acaba de presentar, no se aplica en la práctica por el Municipio ; pues lo corriente es que la tasa supere a los gastos y produzca un remanente. Históricamente, con las ta'sas se ha buscado en los sistemas impositivos el mismo fin que con el arbitrio: allegar recursos para cubrir toda clase de gastos. Los tipos de las tasas, como los de los arbitrios, se fijan y modifican según las necesidades dell fisco, sin preocupaciones doctrinales.

Es por ello que Einaudi, en la clasificación de los medios necesarios para satisfacer los gastos púbilicos, prescinde de las tasas. Este criterio es el que impera actualmente en nuestra Ley de Régimen local, y por consiguiente las tasas que se perciben por la vigilancia 
y reconocimiento sanitario de reses, carnes, pescados, deche, y otros mantenimientos destimado's al abasto público, son prácticamente arbitrios sobre el consumo. El artículo $5 .^{\circ}$ del Reglamento al convertir en arbitrios los derechos y tasas a que se refiere el artículio 440, números 5 y 8, de la Ley de Régimen local no hace más que dar la adecuada forma jurídica a una situación fáctica preexistente. Como consecuencia de la transformación de las tasas antes citardas en arbitrios sobre el consumo éstos se exigirán -al igual que los que gravan las bebidas espirituosas y alcoholes, carnes, volatería y caza menor, y pescados y mariscos finos- mediante tarifas ad valorem que posibilitarán la traslación del impuesto influyendo asi la Hacienda municipal en la coyuntura económica.

Con el fin de conciliar los intereses del Municipio con los del contribuyente, el tipo tributario que resulte con la nueva tarifa no podrá exceder en ell momento de la transformación del promedio global del gravamen, ni las cuotas resultantes de la aplicación del nuevo sistema ad valorem ser inferiores a las que se obtendrían con las antiguas tarifas.

Los arbitrios sobre consumos quedarán refundidos en la parte coincidente, acumulándose los tipos.

Las tasas a que se refieren el número 9 del artículo 440, en cuanto recaigan sobre la propiedad inmobiliaria, y los números 5, I 1 y 12 del artículo 444 de la Ley de Régimen local, quedan refundidos acumulándose sus tipos con el arbitrio sobre la riqueza urbana. Los demás conceptos comprendidios en los artículos 440 y 444 de la Ley de Régimen local que graven la propiedad inmobiliaria, - las actividades y beneficios comenciales o industriales, se unificarán, convirtiéndose en arbitrios, por su total importe, recaudándose mediante un solo recibo.

Con objeto de evitar el retorno a la reiteración impositiva y a la desnaturalización de las tasas, no podrá estabỉecerse ninguna de éstas, aunque sea complementaria, sobre conceptos gravados por las tasas que se conviertan en arbitrios, o sean absorbidos por alguno de ellos.

Las exacciones que mantengan la naturaleza de tasas por prestación de servicios no excederán del coste de los mismos.

Las tasas de los números 2 del artículo 440, 10, 19 y 24 del artículo 444 , y el arbitrio del artículo 498 de la Ley de Régimen local que- 
dan absorbidos por la tasa de estacionamiento de vehículos, de marcado carácter finalista.

Se refundirán en una tasa de saneamiento y limpieza las que autorizan los números 14 y 15 del artículo 440 de la Ley de Régimen local, pudiendo unificarse formalmente con otro concepto en un solo documento cobratorio.

Los artíoulos 64 de la Ley y 9 y 15 del Reglamento, introducen importantes excepciones al precepto del artículo 448 de la Ley de Régimen local. El Ayuntamiento tiene opción para sustituir la participación en los ingresos brutos o netos de las empresas explotadoras de servicios, por la prestación gratuíta al Municipio de los servicios efectuados por la empresa hasta un máximo del 1,50 \% del volumen bruto de suministro que la misma realice en el término municipal. A este efecto se computarán sin excepción todos los servicios o suministros efectuados por las empresas, incluso los "suministros propios» y los que se presten gratuitamente a un tercero. Si el Ayuntamiento no agotare dicho porcentaje la empresa vendrá obligada a satisfacer en metálico la diferencia en la forma prevista en la Ley de Régimen local para la participación en los ingresos brutos o en el producto neto. De igual manera el Ayuntamiento abonará la diferencia que por mayor consumo se hubiese producido.

Las contribuciones especiales son reguladas por la Ley y el Reglamento de acuendo con la más pura ortodoxia dogmática. Veámoslo.

Las contribuciones se pagan por obras que el Municipio construye en ventaja, sobre todo, de la colectividad y que no puede impedirse que redunden también en beneficio de algunas personas privadas. El beneficio prestado a los individuos privados es una consecuencia importante, pero no la finalidad de la obra.

Respondiendo a este principio el artículo io del Reglamento dice que las contribuciones especiales en sus dos modalidades se aplicarán por razón de todos los servicios y obras municipales de primer establecimiento.

La contribución es una compensación por un beneficio producido exclusivamente a la propiedaid inmobiliaria, en consecuencia, estarán sujetas a exacción todas las fincas del término municipal, sin más exenciones $o$ bonificaciones que las dispuestas en el artícuto 468 de la Ley de Régimen locall.

$\mathrm{L}_{a}$ exacción que nos ocupa es una compensación por una obra o servicio prestado a una categoría de personas limitadas territorial- 
mente. El limite territorial allcanzará hasta donde alicance el aumento de valor o el beneficio. Estos se extienden sobre una determinarda zona, como la manoha de aceite sobre ell papel: a la par que se ensandha se diluye. De acuerdo con este principio las contribuciones se aplicarán a una zona que padrá ser más amplia que el polígono o sector objeto de la obra si ésta aumenta el valor o beneficia una mayor área.

Para una justa distribución de la carga entre los interesado's poidrá fijarse la proporción con que deban contribuir las distintas superficies según... las distancias... y cuallesquiera otros elementos.

La contrihución especial es una suma pagada de una sola vez; pero la Ley establece una excepción ouando se trata de cuotas de cierta cuantía, disponiendo d que los propietarios obligados al pago podrán solicitar del Ayuntamiento el fraccionamiento del pago.

La justicia de que las contribuciones especiales deben afectar a los más beneficiados por las obras y servicios y el recto criterio de poner fin a la discrecionalidad en su reparto ha inspirado los preceptos de los ápartados 3,4 y 5 del artículo i4 que las fija según módullos objetivo's que se refieren a fia anchura de la vía pública (I2 o más metros), capacildad de tránsito y especiales motivos de ubicación y uso general de cada calle. Para la más justa distribución de la exacción se llama a contribuir, junto a los propietarios, a los titulares de establecimientos industriales o comercialles.

Para facilitar la gestión de las contribuciones se establece la posibilidad de sustituir el reparto analítico de las cuotas hasta ahora usado, por un tanto alzado de tipo unitario, en proporción, para cada contribuyente, a los metros lineales de fachada del inmueble, a su superficie edificabile o a los volúmenes de edificación, sin que en estos supuestos pueda formarse Asociación de contribuyentes para la realización de las obras o servicios.

El pivote fundamental sobre el que se asienta la Hacienda municipal está constituído por dos nuevos arbitrios: el de radicación, y sobre servicios y adquisiciones, de los cuales se espera la vitalización del erario y una maryor justicia social en la distribución de la carga fiscal, haciéndola resballar hacia el sector comercial e industrial, de prosperidar notoria en la urbe catalana, y hacia el sector de población que exteriorice a'deouada capacidad contributiva. El primero no es un ar- 
bitrio de producto; toda vez que no recae sobre las rentas parciales que obtiene el contribuyente de lia explotación de su negocio, sino un impuesto sobre el capital, entendido éste, como patrimonio adquisitivo y cuya finalidad es gravar el aumento de valor de los bienes.

Elementos técnicos de nuestro Ayuntamiento asignan al arbitrio de radicación el carácter de ufactor correctivo de la excesiva superficie ocupada; y de la relativa importancia viaria de éstan. En su contra, destacados elementos sindicalies pronostican una repercusión negativa en el desarrollo de la economía barcelonesa necesitada de grandes capitales que invertir en la renovación de maquinaria y utillaje.

El señor Porcioles en una magistral conferencia no sólo explicó, sino que demostró que el impuesto es justo y procedente. Justo, porque resume y condensa la participación de los industriales y comerciantes en las obligaciones municipales.

Objeto del anbitrio son las empresas industriales y comerciales que tengan en el término municipal la sede, sucursales, agencias, despachos, fábricas, depósitos, almacenes, etc. Al entrar en vigor este arbitrio dejarán de devengarse las tasas a que se refieren los números 6, 9 y 1o del artículo 440 y 12 y 23 del 444 de la Ley de Régimen local que, entre otras quedarán absorbidas, ya que en total se refunden hasta 18 conceptos que hasta ahora pesaban sobre las empresas comerciales e industriales.

Así, pues, en rendimiento el arbitrio de radicación no será totalmente un nuevo ingreso para la Corporación. Se pretende que el arbitrio no suponga una mayor presión fiscal, sino el logro de una mayor justicia distributiva.

La base está constituida por la superficie ocupada por los establecimientos gravados en función de la diversa importancia y situación de los locales y a la clase de comercio o industria.

El tipo impositivo será como máximo de 25 pesetas por metro cuadrado para las empresas de toida índole radicadas en las vías que se clasifiquen de 8..$^{\text {a }}$ clase. Para cada una de las categorías superiores se incrementarán hasta un $50 \%$ los tipos correspondientes señalados para la categoría inmediata inferior.

Se establecen exenciones totales y parciales. Las primeras benefician a las empresas dedicadas a actividades de educación, sanidad y cultura física.

Las exenciones parciales comprenden a los establecimientos que 
coadyuven con el Ayuntamiento a la solución de los problemas sociales públicos o urbanísticos.

Después de las exenciones la Ordenanza contempla las superficies ocupadas por las empresas y que no están sujetas al arbitrio, tales como, en los locales de espectáculos públicos, toda superficie distinta a la sala y si son al aire libre, la no ocupada por espacios reservados al público. En los restantes establecimientos, las superficies ocupadas por servicios sanitarios, aseos, vestuarios, cocinas, comedores, etc. Asimismo tiene en cuenta da Ordenanza, los locales con fachadas recayentes a dos o más vías públicas, los locales mixtos de vivienda o comercio e industria, la ocupación de un solo local por varias empresas.

La tarifa que grava el metro cuadrado según planta y año, oscila entre 20 pesetas para la clase $8 .^{a}$ y $\mathrm{I} 75$ pesetas para la de $\mathrm{I}^{\mathrm{a}}$ especial. Pero queda graduada en forma que a partir de los $200 \mathrm{~m}^{2}$, la tarifa es decreciente.

Pero además, se disponen dos olases de reducciones; una, sobre la supenficie como base diquidable; otra, sobre la cuota. Tiene por objeto esta reducción distribuir el gravamen con mayor justicia en relación con la actividad desarrollada en la superficie gravada, habiéndose elegido como más justa la tributación de la empresa por el impuesto industrial. Este impuesto relacionado con la rentabilidad de la empresa ha constituído el módulo más justo para evitar la igualdad tributaria entre el negocio rico y el negocio modesto.

El arbitric sobre servicios $y$ adquisiciones no es un gravamen sobre la circulación de la riqueza, sino más bien un impuesto de lujo cuya implantación está condicionaida a la desgravación, por arbitrios y tasas, de otros artículos de primera necesidad. Van a desgravarse hasta 72 especies de artículos alimenticios. Se opera así una laudable redistribución de las rentas al trasladar el impuesto desde los artículos y servicios consumidos por las clases económicamente débiles, a los adquiridos por aquellas otras de mayor capacidad económica. Para que la bondad del arbitrio no se malogre, es menester que en la determinación de los servicios y artículos suntuarios se proceda con un amplio criterio, teniendo en cuenta las exigencias de la vida moderna y el progreso material y espiritual de la civilización occidental.

El tipo de imposición del 5 por Ioo, que se graduará ponderadamente, con fijación de minimos exentos, me parece moderado y 
de fácil percepción. Al facultar al Ayuntamiento para acordar la reducción hasta un 30 por 100 de determinados tipos impositivos de la antigua Tarifa $5 .^{\circ}$ de Usos y Consumos (art. $478 \mathrm{~L}$. R. L.) parece que por fin el leguislador ha comprendido que los tipos del 30 por 100 y 50 por 100 son leoninos $y$, por ende, de dificilísima recaudación. Esta es una excelente coyuntura para eliminar el 5 por 100 que pesa sobre los servicios urbanos de taxi, que el legislador con criterio anacrónico considera un lujo.

Con evidente criterio de justicia social ha sido estructurado el arbitrio sobre estancias, exigible sobre las facturaciones en hoteles de lujo y de $1 .^{a}$ categoria, y compatible con el de consumiciones, y el de consumo de lujo.

Este arbitrio no ha de recaer sobre los barceloneses, sino única y exalusivamente sobre los turistas y demás visifantes que se beneficiaban de llos servicios públicos de la ciudad, sin contribuir a ellos en forma alguna.

El arbitrio sobre el incremento del valor de los terrenos y el que recae sobre el incremento del precio de traspaso de los locales de negocio, tienen la misma naturaleza juridica y la misma justificación fiscal: son impuestos sobre el capital y gravan su plus valia.

El tipo de imposición del primero que era del 25 por 100 del incremento en la Ley de Régimen local ha sido elevado hasta el 50 por 100.

El arbitrio sobre incremento del precio de traspaso tendrá como base el precio, si éste es superior al montante del módufio establecido en la Ordenanza, que se determinará en función de la categoría de la vía pública, de la superficie, renta, destino, y demás circunstancias del local. El precio será el efectivamente satisfecho por la cesión del local, sin existencias (véase art. 29 de la Ley de Arrendamientos urbanos) comprendida la participación que pueda corresponder al propietario (según el art. 39 de la Ley de Arrendamientos urbanos), pero se rebajará de dicho importe el precio que el cerdente acredite haber satisfeoho por la adquisición anterior.

El tipo será $\theta_{i}$ mismo señalado para el arbitrio sobre el incremento de? valor de los terrenos. Al objeto de gravar el incremento constante de valor que experimentan los locales poseídos por personas jurídicas, en sustitución de este arbitrio podrá establecerse una tasa de equivalencia.

Están obligados al pago todos los que intervienen en la cesión: 
1. Los propietarios de las fincas por la participación que les correponda sobre el precio de traspaso según el artículo 39 de la Ley de Arrendamientos urbanos.

2. Los adquirentes o cesionarios de los locales por el resto de la base, deducida la participación anterior, pero con facultad de repercutir el arbitrio sobre el cedente. La Administración trata de asegurar la efectividad de las cuotas diquidadas, para ello nada mejor que considerar sujeto pasivo económico al que ofrece mayor garantía, que es el cesionario, ya que no sólo adquiere el local, sino que puede retener dei cedente el importe del arbitrio directamente, o por amortización del mismo.

Exacciones urbanisticas. E1 articullo 42 del Reglamento es fiel trasunto del artículo I8I de la Ley del Suelo; en consecuencia, las exacciones urbanísticas son las siguientes:

I. Derechos y Tasas. $\left\{\begin{array}{l}\text { Por prestación de servicios. } \\ \text { Por aprovechamientos especiaies. }\end{array}\right.$

2. Contribuciones especiales por obras, instalaciones o servicios.

3. Arbitrio no fiscal sobre edificación deficiente.

4. Multas.

$5 .^{\circ}$ Arbitrios. $\left\{\begin{array}{l}\text { iobre Ordenación urbanística } \\ \text { sobre Contribución territorial riqueza urbana y, } \\ \text { sobre el aumento del volumen de edificación. }\end{array}\right.$

6. Participación del 80 por 100 de las cuotas del Tesoro de la Contribución territorial riqueza urbana.

$77^{\circ}$ Recargos. $\left\{\begin{array}{c}\text { del } 4 \text { por } 100 \text { sobre el liquido imponible rique- } \\ \text { za urbana } y, \\ \text { del } 25 \text { por } 100 \text { del arbitrio sobre el incremen- } \\ \text { to del valor de los terrenos. }\end{array}\right.$

Los Presupuestos ordinario y extraondinario del Ayuntamiento de Barcelona se coordinarán con la política financiera general del Estado.

Ninguna finalidad resultaría de la coordinación de los tributos municipales con los que constituyen el sistema fiscal del Estado, si al propio tiempo no se coordinaran los respectivos presupuestos. A la coondinación de los ingresos ha de seguir forzosamente la del gas- 
to. No olvidemos que el presupuresto ondinario municipal es del orden de los 1.300.000.000 de pesetas. El paso de la Hacienda neutral a la redistribuidora exige la formación de pianes de inversiones públicas como medio para la consecución de fos fines fundamentales de la política financiera. La política monetaria y crediticia se ha de articular con el plan de inversiones en orden al mantenimiento de la estabilidad monetaria y del pleno empleo. La influencia de las inversiones sobre la estabiuidard monetaria es decisiva. En efecto, las alteraciones en dicha estabilidad se deben a desajustes entre el gasto total de la colectividad y la aferta de bienes y servicios. Una elevación del gasto a la que no corresponda un aumento paralelo de la corriente real de bienes, determina la elevación de íos precios. Ahora bien, los dos componentes del gasto total son la inversión y el consumo. Por tanto, para un consumo determinado existe un volumen de inversión compatible con la estabilidad monetaria, sobrepasado el cual se pnoduce una presión inflacionista. De aquí la necesidad de regular dicho volumen a fin de lograr la estabilidard deseada.

Para evitar el idéficit transitorio ide Caja y la subsiguiente operación de Tesorería se consignará en el capítulo $\mathrm{V}$ del estado de gastos del presupuesto ordinario de la Corporación, una partida equivalente al 2 por 100 del importe del mismo destinada exclusivamente a constituir una Reserva de Tesorería. La expresada partida se mantendrá en los presupuestos sucesivos hasta que la Reserva de Tesorería alcance un total equivalente a lla cuarta parte del presupuesto ordinario en curso y dejará de consignarse cuando se alcance esta cantidad. La Reserva figurará en cuenta propia en el Libro de Valores independientes y auxiliares del presupuesto.

Cuando el total debitado en la referida cuenta no alcance al 25 por 100 del presupuesto en curso, se consignará nuevamente en el estado de gastos la partida del 2 por roo.

La cuenta de Reserva de Tesorería podrá nutrirse además con el 50 por 1oo de los superávit que arrojen los presupuestos ordinarios y extraordinarios, no dotados con operación de crédito, que se liquiden, siempre que el expresado superávit no se destine a dotar presupuestos extraordinarios.

Unicamente podrá idisponerse de la Reserva de Tesorería para enjugar un déficit transitorio de Caja, pero en ningún caso para nivelar un presupuesto deficitario. Hasta tal punto ha de observarse 
el principio de la integridard de la Reserva de Tesorería que todo pago con cargo a la indicada cuenta deberá reintegrarse a ésta tan pronto lo permita la liquidez de Caja y siempre dentro del ejercicio en que se efectúe el pago. Se trata de verdaderos anticipos de Caja de carácter reintegrabie con cargo a la cuenta de Reserva de Tesorería.

En la tramitación del presupuesto ordinario caben señalar, con respecto a la Ley de Régimen local, las siguientes especialidades:

I).-el proyecto se eleva a informe de la Comisión municipal ejecutiva ;

2). - la aprobación del proyecto tiene lugar por mayoria de los miembros asistentes;

3).-ei presupuesto se remite a la Dirección General de Administración Local para que previo informe del Servicio Nacional de Inspección y Asesoramiento se eleve a la Dirección General de Régimen Fiscal para su aprobación y,

4).-la resolución de la Dirección Genenal de Régimen Fiscal no agota la vía gubernativa, siendo admisible recurso de alzada ante el Ministro de Hacienda, cuyo acuerdo no sólo pone fin a la via administrativa, sino que es inimpugnablie en vía contencioso-administrativa, lo cual nos parece una importante limitación de las garantias de los administrados.

La tramitación del presupuesto extraordinario no ofrece excepciones notables al régimen común, salvo el corresponder su aprobacón, cuando no requiere operación de crédito, al Director de Régimen Fiscal. En ca'so contrario resuelve el Ministerio de Hacienda contra cuya resolución no se dará recurso alguno, dice el Reglamento, pero hay que entenderlo en el sentido de que no se dará recurso alguno en vía gubernativa.

En las Ondenanzas fiscales el Ayuntamiento podrá declarar segundos contribuyentes a las personas que en el proceso económico ocupen el grado inmediato anterior al que expenda el artículio o preste el servicio gravado imponiéndoles al efecto la obligación de pago que repetirán en los directamente obligados. El antecedente de esta escisión del sujeto pasivo en jurídico y económico hay que buscarlo en el artículo 518, apartado b), de la Ley de Régimen local 
y en la legislación fiscal del Estado que tha hecho de esta figura jurídica una aplicación exclusiva.

Su introducción en la Hacienda docal hará posible lia recaudación de los impuestos, arbitrios y tasas con rapidez y facilidad.

La determinación de la base imponible podrá hacerse por declaración del contribuyente, por concierto fiscal, por padrón o matrícula, por convenio y por evalluación global con autorizacion del Ministerio de Hacienda.

Se crea como órgano técnico para la fijación de las bases de los arbitrios en los casos de no presentación de declaraciones, los Jurados Mixtos de Estimación en los que un funcionario Letrado actuará de Secretario con voz pero sin voto, asumiendo la representación del contribuyente, al cual deberá darse audiencia en el expediente.

Se le conservian al Ayuntamiento ide Barcelona los beneficios fiscales concedidos por los artículos 673 y 674 de la Ley de Régimen local y se le otorga uno nuevo: la Dewda que emita en lo sucesivo, gozará, con la autorización del Ministerio de Hacienda, de los mismos beneficios que la Deuda públioa del Estado, a los efectos de constitución de fianzas, reservas obligatorias e inversiones de entidades de previsión, seguro y ahorro. Este beneficio puede facilitar la colocación o suscripción de las emisiones, pero la adquisición de títulos para formar reservas obligatorias e inversiones de entidades de previsión dependerá, sin duda, de la rentabilidad líquida del papel municipal.

La Ley concede un beneficio a los poseedores de Deuda municipal al eximir los intereses y primas de amortización del impuesto sobre rentas de capital. Con ello no sólo se logrará hacer más rentables estos vailores, sino también estimular a un alza su cotización.

Es paradójico comprobar que los dos Municipios españoles de Hacienda más voluminosa tienen el crédito tan mermado que no puerden emitir Deuda, si no es con un alto porcentaje de quebranto.

La defraudacion en materia de arbitrios se sancionará con multa hasta el quíntuplo de las cuotas que la Hacienda deje de percibir. Este mayor rigor en la penalidald será de resultadios más positivos que el irrisorio duplo de la cuota con que sanciona las infracciones el' artículo 759 de la Ley de Régimen local.

Ia realidad social es flúida y cambiante, el Derecho que el legis- 
lador crea no puede dirigir la evolución social, aspira tan sólo a encauzarla. Es por ello que la disposición finall de la Ley que comentamos establece una cláusula de revisión a fin de adecuar la norma al momento histórico.

E] potencial económico de Barcelona es considerable (3), esperemos que la Ley especial que glosamos permita no sólo sanear la Hacienda municipal, sino también estimular la fase de reactivación económica que hemos iniciado con vistas a la integración europea.

La Carta - dijo el señor Porcioles-, es el gran instrumento que se ofrece a Barcelona para sumarse a este alto concepto de la función pública.

(3) En 1959 la recaudación líquida total en Barcelona y su Provincia por la Hacienda del Estado se cifró en 8.025.000.000 pesetas. En ell mismc año lo recaudado por la Hacienda municipal de Barcelona ascendió a pesetas 1.253 .336 .875 pesetas. La suma de ambas cantidades arroja el montante de 9.278 .336 .875 pesetas. Tomando como base esta cifra y suponiendo que la presión tributaria sea del 20 por 100 de la renta, obtendremos como valor de ésta la cantidad de 46.391 .684 .350 pesetas. Téngase en cuenta que por carecer de datos no se incluye en el cálculo la recaudación líquida de los demás Municipios de la Provincia de Barcelona. 